02

\title{
Анализ оптических свойств наночастиц серебра
}

\author{
(С) С.И. Расмагин, Л.А. Апресян \\ Институт общей фризики им. А.М. Прохорова РАН, \\ 119991 Москва, Россия \\ e-mail: rasmas123@yandex.ru
}

Поступила в редакцию 22.11.2019 г.

В окончательной редакции 22.11.2019 г.

Принята к публикации 29.11.2019 г.

Исследованы оптические свойства наночастиц серебра (nAg), полученных методом лазерной абляции и „зеленого“ синтеза. Цель работы - получение $\mathrm{nAg}$ с заданными свойствами и исследование спектров поглощения (СП) для сравнения временной стабильности растворов $\mathrm{nAg}$. Измерены СП, получены данные электронной спектроскопии и проведено сравнение свойств $\mathrm{nAg}$, полученных разными методами.

Ключевые слова: наночастицы серебра, плазмонный резонанс, оптический спектр поглощения, зеленый синтез, лазерная абляция.

DOI: $10.21883 /$ OS.2020.03.49061.315-19

\section{Введение}

В наноплазмонике и солнечной энергетике исследуются оптические и фотоэлектрические свойства разных металлических наночастиц. Наиболее распространенными являются наночастицы золота и серебра, как наиболее химически устойчивые и стабильные. Существуют различные методы синтеза наночастиц серебра (nAg). $\mathrm{B}$ данной работе были созданы $\mathrm{nAg}$ методами лазерной абляции и зеленого синтеза в водном растворе. Оба этих метода являются простыми, доступными, малозатратными и не требуют дорогого технологического оборудования. Используя метод лазерной абляции, получили $\mathrm{nAg}$ с помощью лазерного импульса и серебряной мишени. Используя метод зеленого синтеза, получили $\mathrm{nAg}$ восстановлением ионов серебра в водных растворах мяты с нитратом серебра $\mathrm{AgNO}_{3}$. Восстановление проходило с помощью химических веществ, входящих в состав мяты (эфирное масло, ментол, белки, сахара, терпиноиды, фенольные кислоты, полифенолы). Оптические свойства $\mathrm{nAg}$, полученных методом лазерной абляции, были исследованы, например, в работах [1-3].

Оптические свойства наночастиц серебра, полученных в результате „зеленого“ синтеза, были описаны в работах [4-13]. Известно, что в $\mathrm{nAg}$ присутствует локализованный плазмон, который при взаимодействии с электромагнитной волной образует локализованный плазмонный резонанс, который сопровождается оптическими эффектами, такими как усиление люминесценции, поглощение света, комбинационное рассеяние и др. [14]. Локализованный плазмонный резонанс на $\mathrm{nAg}$ имеет практическое значение, например, при создании химических и волоконно-оптических сенсоров $[15,16]$.

В данной работе были созданы растворы nAg, синтезированных разными методами, получены и проанализированы их спектры оптического поглощения, проведен анализ данных электронной спектроскопии, даны оценки их структурных параметров (формы, размера).

Цель данной работы - 1) синтезировать и исследовать оптические свойства $\mathrm{nAg}$, полученных методами лазерной абляции и зеленого синтеза; 2) сравнить временную стабильность их растворов.

\section{Экспериментальная часть}

Для получения nAg методом лазерной абляции использовали импульсный лазер и мишень в виде кусочка чистого серебра в водном растворе. Импульсный лазер с излучением на длине волны $1064 \mathrm{~nm}$ имел длительность импульса $10 \mathrm{~ns}$, частоту $5 \mathrm{~Hz}$ и энергию $1 \mathrm{~mJ}$ в импульсе. Излучение фокусировалось в круглое пятно размером $10 \mu$. Предполагается, что $\mathrm{nAg}$ образуются в результате нуклеации и роста в лазерной плазме.

Для получения nAg зеленым синтезом использовали водные растворы растительных экстрактов, нагретых до $60^{\circ} \mathrm{C}$. Растворы листьев мяты $(6 \mathrm{~g}$ на $100 \mathrm{ml}$ деионизованной воды) нагревали $15 \mathrm{~min}$ в кипящей водяной бане, а затем охлаждали до комнатной температуры в течение $45 \mathrm{~min}$. Полученные фитоэкстракт мяты и отжим из листьев мяты отфильтровали через бумажные фильтры. Цвет полученных экстрактов мяты - желтоватозеленый. Для биосинтеза $\mathrm{nAg}$ к $50 \mathrm{ml} 0.006 \mathrm{M}$ раствора $\mathrm{AgNO}_{3}$ добавляли $2.5 \mathrm{ml}$ приготовленного фитоэкстракта мяты. Концентрация водного раствора $\mathrm{AgNO}_{3}$ составила $1 \mathrm{mg} / \mathrm{ml}$. Индикаторная бумага показала, что среда растворов $\mathrm{nAg}$ с мятой нейтральна. Полученные растворы оставляли на сутки при комнатной температуре. Дальнейшие наблюдения и экспериментальные исследования проводились при температуре $t=23^{\circ} \mathrm{C}$. Спектры поглощения (СП) наночастиц в водных растворах измеряли с помощью спектрометра Ocean Optics USB2000 и лампы LS-1 в качестве источника возбуждающего 
света. Погрешность измерений спектрометра составляет $5 \%$. Диапазон СП изменялся в пределах $300-1100 \mathrm{~nm}$. Мощность галогеновой лампы $10 \mathrm{~mW}$.

\section{Результаты и их обсуждение}

В результате лазерной абляции водный раствор с серебряной мишенью приобрел светло-желтый цвет. Окраска зависела от длительности процесса лазерной абляции.

Внешний осмотр растворов мяты с нитратом серебра показал, что введение раствора соли в водный раствор фитоэкстракта приводит к резкому изменению окраски раствора от светлых оттенков до темно-коричневого. Окраска растворов изменяется в зависимости от концентрации образующихся nAg. Изменение окраски раствора мяты от светло-зеленого до темно-коричневого связано с появлением характерной для коллоидных $\mathrm{nAg}$ плазмонной полосы поглощения с длиной волны в районе $400 \mathrm{~nm}$

Физико-химический процесс создания $\mathrm{nAg}$ на примере ментола состоит из следующих стадий.

1) Восстановление атомов серебра (химическая реакция), $\mathrm{Ag}^{+} \mathrm{NO}_{3}^{-2}+\left(\mathrm{C}_{10} \mathrm{H}_{19}\right)^{+}(\mathrm{OH})^{-}=\mathrm{Ag}^{0}+\left(\mathrm{C}_{10} \mathrm{H}_{19}\right)^{+}=$ $=\mathrm{O}^{-}+\mathrm{H}^{+} \mathrm{NO}_{3}^{-2}$.

2) Образование зародышей (ван-дер-ваальсово взаимодействие $), \quad \mathrm{Ag}^{0}+\left(\mathrm{C}_{10} \mathrm{H}_{19}\right)^{+}=\mathrm{O}^{-} \mathrm{H}^{+} \mathrm{NO}_{3}^{-2}=$ $\left.=\left(\mathrm{Ag}^{0}\left(\mathrm{C}_{10} \mathrm{H}_{19}\right)^{+}=\mathrm{O}^{-}\right)\right)+\mathrm{H}^{+} \mathrm{NO}_{3}^{-2}$.

3) Рост и образование $\mathrm{nAg}$ (мицелл), $\left(\mathrm{Ag}^{0}\left(\mathrm{C}_{10} \mathrm{H}_{19}\right)^{+}=\right.$ $\left.=\mathrm{O})+\mathrm{H}^{+} \mathrm{NO}_{3}^{-2}=\left\{\left(\mathrm{Ag}^{0}\left(\mathrm{C}_{10} \mathrm{H}_{19}\right)^{+}=\mathrm{O}^{-}\right)\right) \mathrm{H}^{+}\right\}+\left(\mathrm{NO}_{3}^{-2}\right)$, состоящих из металлического ядра $\mathrm{Ag}^{0}$, оболочки $\left(\mathrm{C}_{10} \mathrm{H}_{19}\right)^{+}=\mathrm{O}^{-}$и противоионов $\mathrm{H}^{+}$.

Провели исследования полученных растворов на сканирующем электронном микроскопе с целью оценить форму и размеры $\mathrm{nAg}$. В результате получили следующие электронные микрофотографии, приведенные на рис. 1 и 2.

Анализируя данные микрофотографий, видим, что большинство $\mathrm{nAg}$ имеют сферическую форму, и их размеры находятся в области $20-30 \mathrm{~nm}$ (рис. 1) и 35-40 nm (рис. 2).

Были измерены CП nAg, созданных лазерной абляцией (рис. 3). СП сняты в зависимости от длительности времени после создания $\mathrm{nAg}$ (далее просто времени жизни $\mathrm{nAg}$ ).

График с обозначением 1 соответствует измерению СП в через $1 \mathrm{~h}$ после его изготовления. Соответственно графики $2-72 \mathrm{~h}, 3-120 \mathrm{~h}, 4-168 \mathrm{~h}, 5-216 \mathrm{~h}$ и $6-240 \mathrm{~h}$. График 1 на рис. 3 показывает, что СП имеет характерную полосу поглощения с максимумом, соответствующим длине волны $400 \mathrm{~nm}$. Причиной появления этой полосы (так называемого плазмонного резонанса) является взаимодействие электромагнитного поля светового излучения с электронами проводимости nAg. Когда частота колебаний световой волны совпадает с собственной частотой коллективных колебаний

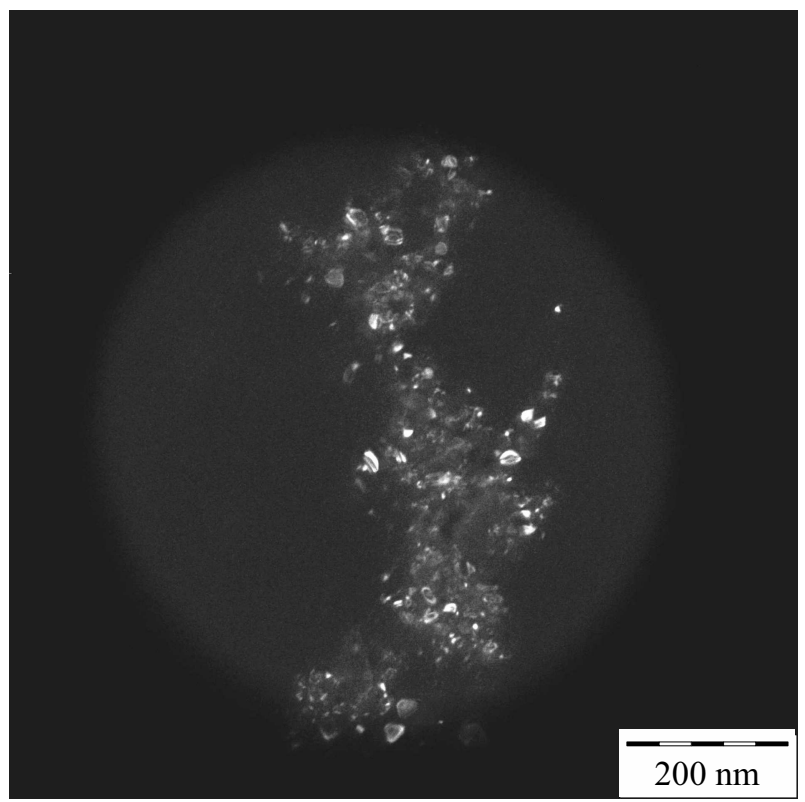

Рис. 1. Изображения СЭМ nAg, полученных лазерной абляцией.

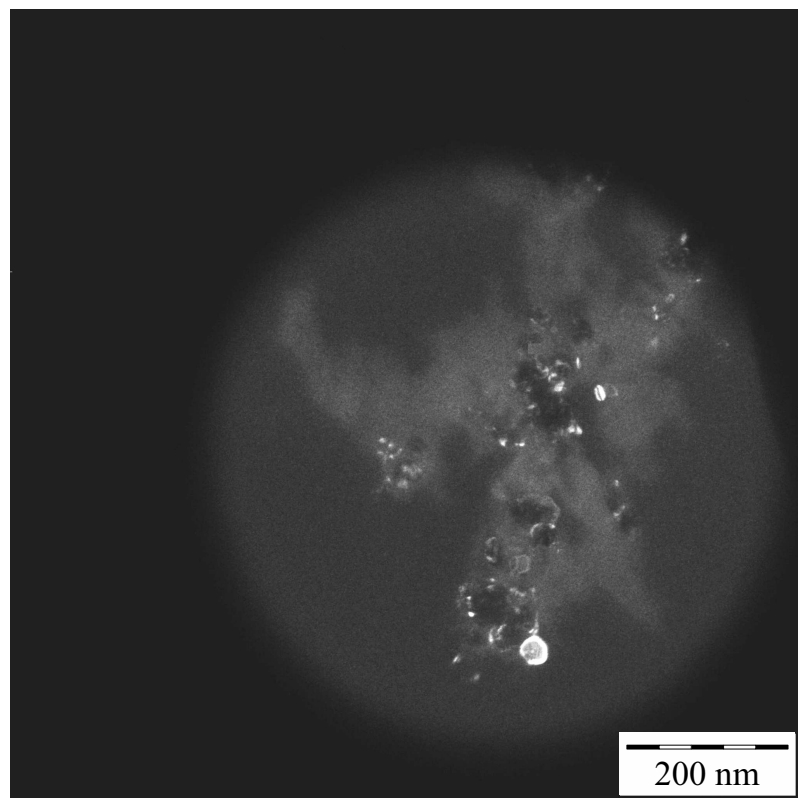

Рис. 2. Изображения СЭМ nAg, созданной зеленым синтезом.

электронов в $\mathrm{nAg}$, наблюдается резонансное увеличение поглощения и рассеяния света [17]. Положение максимума, интенсивность и форма полосы поглощения $\mathrm{nAg}$ зависят от их размеров и формы, типа стабилизации и свойств окружающей жидкой среды. Из рис. 3 видно, что с течением времени СП $\mathrm{nAg}$ постепенно изменяется. $\mathrm{C}$ увеличением времени жизни $\mathrm{nAg}$ величина максимума СП уменьшается, а сам максимум смещается в длинноволновую область. Если сравнить СП, измеренный через $240 \mathrm{~h}$ после синтеза $\mathrm{nAg}$, с СП через $1 \mathrm{~h}$, то 


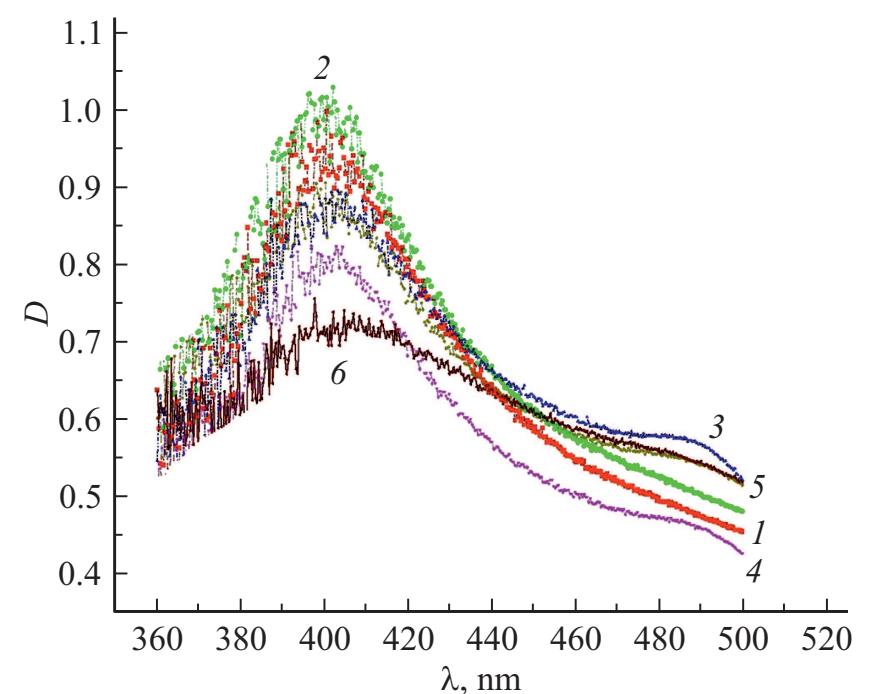

Рис. 3. СП растворов $\mathrm{nAg}$ в зависимости от времени жизни $\mathrm{nAg}: 1-1 \mathrm{~h}$ после создания $\mathrm{nAg}, 2-72 \mathrm{~h}, 3-120 \mathrm{~h}, 4-$ $168 \mathrm{~h}, 5-216 \mathrm{~h}$ и $6-240 \mathrm{~h}$. Лазерная абляция.

величина максимума уменьшилась в 1.4 раза, а сам максимум сместился от 400 до $412 \mathrm{~nm}$. Спад максимума СП вызван уменьшением концентрации наночастиц $\mathrm{nAg}$. Данное уменьшение обусловлено сильной коагуляцией $\mathrm{nAg}$ в более крупные частицы и выпадением их в осадок. Остальная (уменьшенная) часть $\mathrm{nAg}$ имеет размер порядка $20-30 \mathrm{~nm}$ и по-прежнему дает вклад в плазмонный резонанс. Батохромный сдвиг на $12 \mathrm{~nm}$ также можно объяснить увеличением размера $\mathrm{nAg}$ изза коагуляции с течением времени. Полуширина спектра для $\mathrm{nAg}$ раствора 1 (измеренного в день его создания) составила порядка $50 \mathrm{~nm}$. Данное уширение СП вызвано в основном кулоновским и в меньшей степени ван-дерваальсовым взаимодействием $\mathrm{nAg}$. Из рис. 3, видно, что полуширина СП с течением времени жизни $\mathrm{nAg}$ незначительно увеличивается в диапазоне $50-65 \mathrm{~nm}$. Это дополнительное уширение спектров $\mathrm{nAg}$ может быть вызвано ван-дер-ваальсовым взаимодействием nAg с более крупными частицами, не выпавшими в осадок.

На основе данных СП были сделаны оценки размеров nAg и их оболочки, а также дана оценка концентрации в водном растворе [18]. Оценки были сделаны на основании классической теоретической модели для металлических шаров, представленной в [19]. В этой модели спектр диэлектрической проницаемости раствора описывается с помощью спектра диэлектрической проницаемости объёмного металла и окружающей среды, а влияние размера частиц учитывается как увеличение частоты столкновений электронов в металле. В конечном итоге плазменная частота металла и показатель преломления окружающей среды задают положение максимума СП коллоидного раствора, высота которого определяется объёмной долей металла, а ширина - частотой столкновений электронов с учётом вклада, связанного с раз- мерами наночастиц металла. Применяя данную модель к СП, получили следующие оценки: средний размер $\mathrm{nAg}$ порядка $20 \mathrm{~nm}$, размер диэлектрической оболочки (предположительно $\left.\left(\mathrm{C}_{10} \mathrm{H}_{19}\right)^{+}=\mathrm{O}^{-}\right)$порядка $-30 \mathrm{~nm}$, концентрация серебра в коллоидном растворе $6 \cdot 10^{-5} \mathrm{M}$. Сравнивая размер $\mathrm{nAg}$, полученных из СП $(d=20 \mathrm{~nm})$, и размер $\mathrm{nAg}$, полученных методом электронной микроскопии $(d=20-30 \mathrm{~nm})$, видим, что размеры $\mathrm{nAg}$ близки. Итак, используемую выше модель можно с хорошей точностью применять для оценки размеров и оболочки nAg.

Были измерены CП nAg, созданных зеленым синтезом (рис. 4). СП сняты в зависимости от времени жизни nAg.

График с обозначением 1 соответствует измерению СП через $1 \mathrm{~h}$ после его изготовления. График 2 соответствует измерению СП через $120 \mathrm{~h}$, график 3 соответствует измерению СП через $240 \mathrm{~h}$. Анализируя графики рис. 4 , были установлены следующие экспериментальные факты. Величина пика СП растет с увеличением времени жизни $\mathrm{nAg}$. Пик незначительно смещается в длинноволновую область с 437 до $445 \mathrm{~nm}$. Полуширина СП увеличивается на $10 \mathrm{~nm}$ от $\Delta \lambda=130 \mathrm{~nm}$ до $\Delta \lambda=140 \mathrm{~nm}$. Если сравнить СП, измеренный через $240 \mathrm{~h}$ после синтеза $\mathrm{nAg}$, с СП, измеренным через $1 \mathrm{~h}$, то величина максимума выросла в 1.6 раза. Рост оптический плотности $D$ с увеличением времени жизни $\mathrm{nAg}$ вызван увеличением концентрации $\mathrm{nAg}$. Очевидно, что восстановление ионов серебра благодаря фитоэкстракту мяты с нитратом серебра $\mathrm{AgNO}_{3}$ продолжалось в течение всех $240 \mathrm{~h}$. Были определены концентрация $\mathrm{nAg}$ - порядка $2 \cdot 10^{-5} \mathrm{M}$. Были оценены размеры nAg с помощью модели [19] (порядка $35-40 \mathrm{~nm}$ ), которые совпали с размерами на микрофотографии СЭМ (рис. 2).

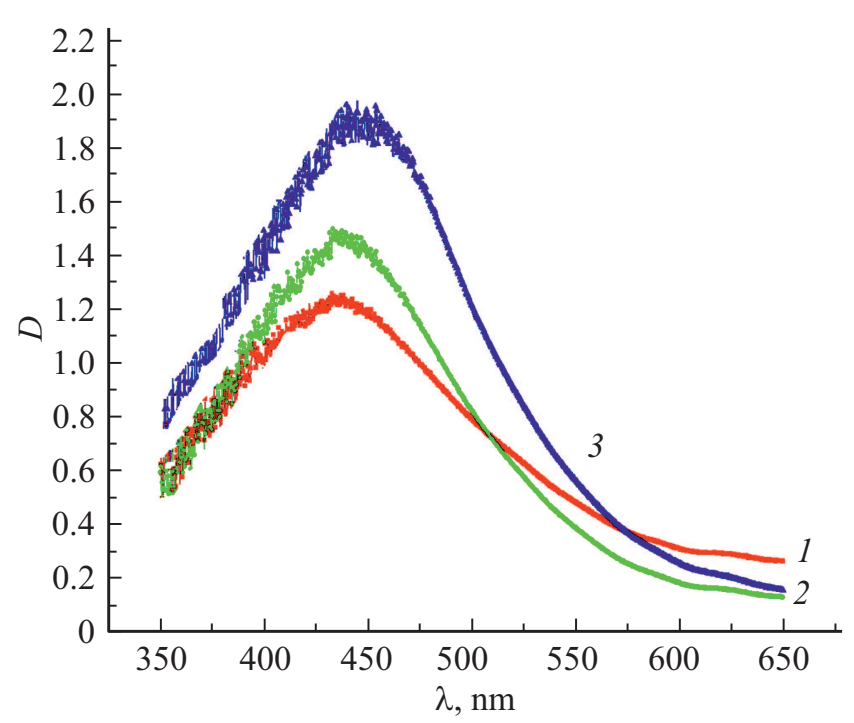

Рис. 4. СП растворов $\mathrm{nAg}$ в зависимости от времени жизни $\mathrm{nAg}: 1-\mathrm{nAg}$, измеренные через $1 \mathrm{~h}$ после их создания, $2-$ $120 \mathrm{~h}$ после создания nAg, 3 - 240 h. Зеленый синтез. 
Сравнивая оптические параметры СП растворов $\mathrm{nAg}$, полученных лазерной абляцией и зеленым синтезом, пришли к следующим заключениям.

1. Величина $(D=1.2-2)$ пиков СП растворов $\mathrm{nAg}$, полученных зеленым синтезом, больше, чем пиков $(D<1) \mathrm{CП} \mathrm{nAg,} \mathrm{полученных} \mathrm{лазерной} \mathrm{абляцией.} \mathrm{Факт}$ объясняется большей концентрацией $\mathrm{nAg}$, полученных зеленым синтезом, по сравнению с $\mathrm{nAg}$, полученными лазерной абляцией.

2. Пики СП $\left(\lambda_{m}=437-445 \mathrm{~nm}\right)$ растворов $\mathrm{nAg}$, полученных зеленым синтезом, смещены более сильно в длинноволновую область по сравнению с пиками СП $\left(\lambda_{m}=400-412 \mathrm{~nm}\right) \mathrm{nAg}$, созданных лазерной абляцией. Это объясняется следующими факторами: большим размером nAg, полученных зеленым синтезом, по сравнению с размерами $\mathrm{nAg}$, полученных лазерной абляцией, образованием внешней оболочки $\mathrm{nAg}$ и агрегацией химических веществ мяты на поверхности $\mathrm{nAg}$.

3. Полуширина $(\Delta \lambda=130-140 \mathrm{~nm})$ СП растворов $\mathrm{nAg}$, полученных зеленым синтезом, превосходит в 2.8 раза полуширину $(\Delta \lambda=50-60 \mathrm{~nm}) \mathrm{CП} \mathrm{nAg,} \mathrm{по-}$ лученных лазерной абляцией. Значительное уширение $\mathrm{C \Pi} \mathrm{nAg} \mathrm{вызвано} \mathrm{взаимодействием} \mathrm{nAg}$ с химическими веществами, входящими в состав мяты.

Так как nAg, созданные зеленым синтезом, практически не коагулируют в течение $240 \mathrm{~h}$ (в отличие от $\mathrm{nAg}$, созданных лазерной абляцией), то целесообразно использовать именно их бактерицидное действие в медицинских материалах (бинты, лейкопластырь и др.).

\section{Заключение}

Анализируя СП и данные электронной микроскопии приходим к следующим заключениям.

1. Определены основные параметры „зеленого“ синтеза (концентрация, температура, состав).

2. Экспериментально определены форма (в основном сферическая), размеры ( $d=20-30 \mathrm{~nm})$ и концентрация $6 \cdot 10^{-5} \mathrm{M} \mathrm{nAg}$, полученных лазерной абляцией.

3. Экспериментально определены форма (в основном сферическая), размеры $(d=35-40 \mathrm{~nm})$ и концентрация $2 \cdot 10^{-5} \mathrm{M} \mathrm{nAg,} \mathrm{полученных} \mathrm{зеленым} \mathrm{синтезом.}$

4. nAg, полученные лазерной абляцией, коагулируют с течением времени, что приводит к уменьшению их концентрации и ослаблению плазмонного резонанса. $\mathrm{nAg}$, созданные зеленым синтезом, практически не коагулируют с течением времени в наших экспериментальных условиях. При этом плазмонный резонанс практически усиливается с течением времени.

\section{Конфликт интересов}

Авторы заявляют, что у них нет конфликта интересов.

\section{Список литературы}

[1] Симакин А.В., Воронов В.В., Шафеев Г.А. // Труды ИОФАН. 2004. Т. 60. С. 83-107.

[2] Светличный В.А., Изаак Т.И., Бабкина О.В., Шабалина А.В. // Известия вузов. Физика. 2009. Т. 52. № 12/2. C. $110-115$.

[3] Булгаков А.В., Булгакова Н.М., Бураков И.М. и др. Синтез наноразмерных материалов при взаимодействие мощных потоков энергии на вещество. Новосибирск: Институт теплофизики СО РАН, 2009. 462 c.

[4] Chenopodium Album Leaf Extract // Colloids and Surfaces. A: Physicochem. Eng. Aspects. 2010. V. 369. P. 27-33.

[5] Расмагин С.И., Апресян Л.А., Крыштоб В.И., Красовский В.И. // Прикладная физика. 2018. № 2. С. 64-69.

[6] Rauwel P., Küünal S., Ferdov S., Rauwel E. // Adv. Mater. Sci. Eng. 2015. V. 2015. P. 1-9.

[7] Rasmagin S.I., Krasovskii V.I., Novikov I.K., Kryshtob V.I., Kazaryan M.A. // Proc. SPIE 10614, International Conference on Atomic and Molecular Pulsed Lasers XIII, 1061408 (16 April 2018). doi 10.1117/12.2302987

[8] Iravani S. // Green Chem. 2011. V. 13. P. 2638-2650.

[9] Расмагин С.И., Крыштоб В.И., Новиков И.К. // Неорганич. материалы. 2018. Т. 54. № 9. С. 918-923. doi 10.1134/S0020168518090121

[10] Макаров В.В., Лав А., Синищина О.В., Макарова С.С., Яминский И.В., Тальянский М.Э., Калинина Н.О. // Acta Nature. 2014. V. 6. N 1 (20). P. 37-47.

[11] Расмагин С.И., Крыштоб В.И., Новиков И.К. // ЖТФ. 2018. T. 88. № 12. С. 1868-1872.

[12] Govindaraju K., Khaleel Basha S., Ganesh Kumar V., Singaravelu G.J. // Materials Sci. 2008. V. 43. P. 5115-5122.

[13] Harris A.T., Bali R.J. // Nanoparticle Res. 2008. V. 10. P. 691-695.

[14] Krutyakov Yu.A. et al. // Rus. Chem. Rev. 2008. V. 77. N 3. P. 233-257.

[15] Polman A. // Plasmonics Appl. Sci. 2008. V. 322. N 5903. P. $868-869$.

[16] Дышлюк А.В., Витрик О.Б., Lи Gиоһиi, Кульчин Ю.Н. // Письма в ЖТФ. 2015. Т. 41. В. 12. С. 56-58.

[17] Evanoff D.D., Chumanov G. // ChemPhysChem. 2005. V. 6. P. $1221-1231$.

[18] Караванский В.А., Симакин А.В., Красовский В.И., Иванченко П.В. // Квант. электрон. 2004. Т. 34. № 7. С. 644-648.

[19] Mandal S.K., Roy R.K., Pal A.K. // J. Phys. D: Appl. Phys. 2002. V. 36. P. 2196. 